\title{
Моделирование методом Монте-Карло структуры поверхности эпитаксиального слоя Si, выращенного в условиях МЛЭ
}

Арапкина Л.В.

ИОФ РАН, 119991, Москва, ул.Вавилова, 38

DOI 10.34077/Semicond2019-89

Представленная работа посвящена исследованию структурных свойств поверхности эпитаксиальных слоев $\mathrm{Si}$, выращенных методом молекулярно-лучевой эпитаксии (МЛЭ) в режиме pocта step-flow. Методом сканирующей туннельной микроскопии изучено строение поверхности слоев $\mathrm{Si}$, выращенных на $\mathrm{Si}(001)$ с углами наклона от $0.12^{\circ}$ до $0.9^{\circ}$ в направлении [110]. Установлено, что по-мере увеличения угла наклона поверхности подложки $\mathrm{Si}(001)$ на поверхности эпитаксиального слоя Si наблюдается переход от структуры с преобладающими Тb террасами к структуре с равными по ширине террасами [1]. Методом Монте-Карло проведено моделирование процесса роста. Модель основана на допущении о влиянии полей упругих напряжений, возникающих на поверхности $\operatorname{Si}(001)$ [2], на проницаемость моноатомных ступеней. Проницаемость ступени определяет возможность перехода атома через край ступени без встраивания в нее. В равновесных условиях релаксация полей упругих напряжений способствует формированию на поверхности террас равной ширины. Известно, что поверхность $\mathrm{Si}(001)$ сформирована моноатомными ступенями двух типов: $\mathrm{S}_{\mathrm{a}}$ и $\mathrm{S}_{\mathrm{b}}$ [1]. Строение, энергии образования этих ступеней различны, что приводит к разной скорости их продвижения во время роста $[3,4]$ и должно бы было способствовать формированию двухатомных ступеней типа $\mathrm{Db}$. Согласно экспериментальным данным формирование ступеней типа $\mathrm{D}_{\mathrm{b}}$ наблюдается при больших значениях углов разориентации $\mathrm{Si}(001)$ [5]. В исследуемом диапазоне углов наклона ростовая поверхность образована моноатомными ступенями. В условиях роста стабильная структура ростовой поверхности (постоянная ширина террас) поддерживается за счет одинаковой скорости продвижения моноатомных ступеней $\mathrm{S}_{\mathrm{a}}$ и $\mathrm{S}_{\mathrm{b}}$ типа. В модели предполагается, что влияние полей упругих напряжений на ширину моноатомных террас зависит от угла наклона поверхности $\operatorname{Si}(001)$. Чем он меньше, тем более вероятным становится процесс формирования террас разной ширины. Равная скорость продвижения соседних моноатомных ступеней поддерживается изменением их проницаемости в зависимости от расстояния между ними. Результаты моделирования подтверждаются данными СТМ исследования. Исследуемые образцы выращивались методом МЛЭ на установке Riber EVA 32 при температуре $650^{\circ} \mathrm{C}$ в режиме роста step-flow. СТМ исследования проводились при помощи микроскопа GPI-300, присоединенного к ростовой камере через высоковакуумный шибер. В ходе исследования образцы на воздух не выносились.

[1] D.J. Chadi, Phys.Rev.Lett. 59(4) 1691 (1987).

[2] O.L. Alerhand, D. Vanderbilt, R.D. Meade, and J.D. Joannopoulos, Phys. Rev. Lett. 61, 1973 (1988).

[3] H.J. Zandvliet, Rev. Mod. Phys. 72 (2) 593 (2000).

[4] Y.-W. Mo, B.S.Swartzentruber, R.Kariotis, M.B.Webb, and M.G.Lagally, Phys. Rev. Lett. 63(21), 2393 (1989).

[5] B.S. Swartzentruber, N. Kitamura, M.G. Lagally, and M.B.Webb, Phys. Rev. B 47,13432 (1993). 